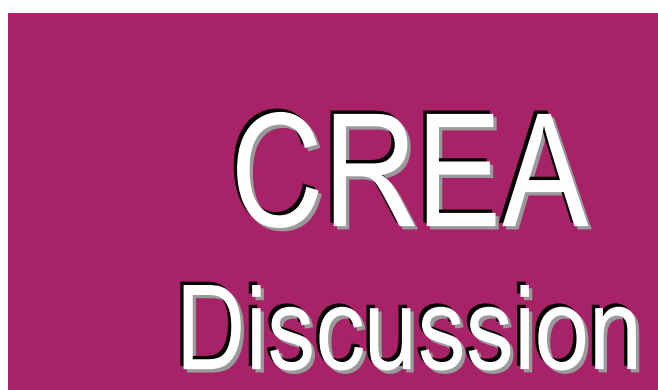
Paper 2019-06 Economics

\title{
Body Mass Index and Social Interactions from Adolescence to Adulthood
}

available online : http://wwwfr.uni.lu/recherche/fdef/crea/publications/discussion_papers

Luisa Corrado, University of Rome Tor Vergata, Italy Roberta Distante, University of Copenhagen \& Nordea, Denmark

Majlinda Joxhe, CREA, University of Luxembourg

May, 2019

For editorial correspondence, please contact: crea@uni.lu University of Luxembourg Faculty of Law, Economics and Finance 162A, avenue de la Faïencerie L-1511 Luxembourg 


\title{
Body Mass Index and Social Interactions from Adolescence to Adulthood*
}

\author{
Luisa Corrado $^{\dagger} \quad$ Roberta Distante Majlinda Joxhe $^{\ddagger}$
}

This Version: May 5, 2019.

\begin{abstract}
We apply a dynamic linear-in-means model to analyze the importance of social ties for the body-weight-related behavior of US youth. Our methodology shows how to estimate peer effects free of the "reflection problem" in a dynamic context where individual- and group-specific unobservable effects are controlled for. Our results show that the main drivers for the body-weight-related behavior are past and peer effects. For individuals who were normal-weight or obese during adolescence, past and peer effects are shown to be both relevant. Peer effects, instead, explain more the variation in the BMI for individuals who were over-weight during adolescence, showing in this way the importance of social interactions for body-weight-related behavior.
\end{abstract}

Keywords: Over-weight, Obesity, Peer Effects, Social Networks, Personal History, Dynamic Linear-in-means Model.

JEL Classification: C01; D10; D71; I19; J11; Z13

${ }^{*}$ We want to thank Gautam Tripathi, Antonio Cosma and all the participants of the Add-Health Conference, 2018. For a non-technical note of the original research project which was using the public access version of the Add-Health data see https://www.feem.it/en/news/feem-re3-obesity-is-contagiousevidence-from-us-data-/.

${ }^{\dagger}$ Department of Economics and Finance, University of Rome Tor Vergata, Italy. E-mail: luisa.corrado@uniroma2.it. Luisa Corrado gratefully acknowledges the RSA Membership Grant Scheme 2016

${ }^{\ddagger}$ University of Copenhagen \& Nordea, Denmark. E-mail: roberta.distante@nordea.dk

${ }^{\S}$ CREA- Center for Research in Economic and Management, University of Luxembourg. E-mail: majlinda.joxhe@uni.lu 


\title{
Body Mass Index and Social Interactions from Adolescence to Adulthood
}

Word Count: 7157

May 5, 2019

\begin{abstract}
We apply a dynamic linear-in-means model to analyze the importance of social ties for the body-weight-related behavior of US youth. Our methodology shows how to estimate peer effects free of the "reflection problem" in a dynamic context where individual- and group-specific unobservable effects are controlled for. Our results show that the main drivers for the body-weight-related behavior are past and peer effects. For individuals who were normal-weight or obese during adolescence, past and peer effects are shown to be both relevant. Peer effects, instead, explain more the variation in the BMI for individuals who were over-weight during adolescence, showing in this way the importance of social interactions for body-weight-related behavior.
\end{abstract}

Keywords: Over-weight, Obesity, Peer Effects, Social Networks, Personal History, Dynamic Linear-in-means Model.

JEL Classification: C01; D10; D71; I19; J11; Z13 


\section{Introduction}

According to the World Health Organization (WHO), there are more than one billion overweight adults worldwide, at least three hundred million of them obese, and these figures are even worse when considering children and adolescents. ${ }^{1}$ The rising phenomenon reflects significant changes in eating behavioral patterns of individuals: over-consumption of carbohydrates and saturated fats as well as scarce physical activity are important causes. However, social and peer effects likely act as drivers of such a large-scale phenomenon, that seems to occur independent of cultural, economic, and environmental circumstances (Andreyeva et al., 2011; Cohen-Cole, 2006; Christakis and Fowler, 2007; Trogdon et al., 2008; Fortin and Yazbeck, 2011; Yakusheva et al., 2011; Gwozdz et al., 2015). Indeed, many epidemic phenomena occur because they spread within social groups through the homogenization of behaviors among individuals of the same group (Manski, 2000): hence, the propensity of a person to behave in a certain way varies positively with the dominant behavior in her group, similar to informal enforcement mechanisms or social norms (Kandori, 1992; Bernheim, 1994). ${ }^{2}$

The aim of the present paper is to estimate the impact of social and peer effects on body-weight-related behavior of US adolescents who transition into adulthood. ${ }^{3}$ By means of a novel, yet simple, empirical approach, we overcome the problem of identifying the impact of social endogenous effects on individual Body Mass Index (BMI). Furthermore, we examine to what extent adulthood BMI status depends on past (what we call "habituation") and peers (what we call "conformity or imitation") during adolescence. Adopting the notion first introduced by Manski (1993), we can identify three types of group effects impacting on individual behavior: endogenous effects, which occur when individual behavior varies with the behavior of the group; contextual effects, that arise when peer group characteristics directly affect individual behavior; correlated or group (unobservable) effects, that arise because group members share a common environment or common latent traits that affect their individual behavior. Analyzing the statistical effect of social interactions is generally challenging due to a special kind of identification problem, the so called "reflection problem" (Manski, 1993): in a linear-in-means model of social interactions, the distinct role of endogenous and contextual effects may be difficult to disentangle because such effects co-move. Since the work of Manski (1993), many are the studies that tackle the estimation of peer effects (see Brock and Durlauf, 2001; Graham and Hahn, 2005; Moffitt, 2001 for a review of the literature).

Recent empirical work seems characterized by writhed frameworks that require information on the network structure (Bramoullé et al., 2009; Calvo-Armengol et al., 2009; Fortin and Yazbeck, 2011, De Paula et. al 2018) or on out of group effects (CohenCole, 2006). ${ }^{4}$

\footnotetext{
${ }^{1}$ See also Philipson (2001).

${ }^{2}$ Peer effects have been extensively examined both in education (Bénabou, 1993) and in psychology (Brown, 1990; Brown et al. 1996). For a review of the literature on social interaction effects see Brock and Durlauf (2001).

${ }^{3}$ The expression 'body-weight-related behavior' comprises all the actions having influence on body weight, e.g. quantity and quality of food, physical exercise, and lifestyle-related issues.

${ }^{4}$ Specifically, Cohen-Cole (2006) uses out of group effects to identify endogenous and contextual effects. However, the method does not take into account individual- and group-specific unobservable effects. In another more recent paper, De Giorgi et al. (2010) show that, in a context where peer groups do not overlap fully, it is possible to identify all the relevant parameters of the standard linear-in-means model of social interactions. The Instrumental Variable approach proposed in their paper, though, while properly accounting for correlated unobservable effect at the group level, does not provide a separate estimation
} 
Different from this literature, ${ }^{5}$ we resort to a simple framework to identify social endogenous effects by using a linear-in-means framework. Specifically, we estimate a dynamic linear-in-means model that allows individual behavior to linearly depend on individual past behavior as well as on group-specific effects, which include some group observable characteristics and the expected aggregate behavior of the others in the group. Such an assumption makes sense when not only choice is thought of as being the result of social and peer effects, but also of past behavior. Past as well as social behavior are possible determinants of individual choice, especially in the case of eating decisions. Furthermore, our econometric strategy allows us to control for endogeneity, individual and group heterogeneity by exploiting stationarity restrictions of a system GMM estimator augmented to control for individual- and group-specific unobservable effects.

We make use of the National Longitudinal Study of Adolescent Health (Add Health Restricted Version) dataset, a (US) representative sample of adolescents and their transition into early adulthood for which information on demographic, health and socioeconomic status is registered along four waves, from 1994 to $2008 .^{6}$

We are able to study the behavioral causes of over-weight and obesity among teenagers, and the effects of such behavior during their transition to adulthood. In contrast to Cohen-Cole and Fletcher (2008), who also focus on obesity and social interactions using the Add Health dataset, the results of our dynamic linear-in-means model show that the tendency of individuals to become over-weight is the outcome of both social effects and past individual behavior. Cohen-Cole and Fletcher (2008) general finding is that social interactions with closest peers are not significant once fixed effects for social groups and individuals are accounted for. In our estimation, instead, social endogenous effects - i.e., the tendency to be affected by the behavior of others in the same grade - are still present even after accounting for school and individual effects.

Our estimation results show that variation in average group BMI produces a significant variation in the individual BMI status, in line with the evidence reported in Christakis and Fowler (2007) and Trogdon et al. (2008). The former study analyzes data on a social network of people pertaining to the Framingham Offspring Study, finding that a person's chance of becoming obese increases by $57 \%$ if a friend became obese in a given interval. The latter makes use of Add Health data to estimate a coefficient of friends' average BMI of about 0.50. However, on the one hand Christakis and Fowler (2007) make use of a statistical method which ignores school and individual effects, and are criticized by Cohen-Cole and Fletcher (2008) as their results may not merely represent endogenous social interactions. On the other hand, Trogdon et al. (2008) base their identification of peer effects on an instrumental variable estimation in a cross-sectional analysis, where

of unobservable effects at the individual and group level.

${ }^{5} \mathrm{~A}$ recent working paper by Verdier (2015) proposes a linear-in-means model for panel data and shows that peer effects can be identified with more general forms of homophily and confounding factors, independently of whether a model with leave-one-out averages or averages is used. Our model, differently from Verdier, imposes some restrictions especially on the fact that the composition of the peer group does not change over time, an assumption which is very close to the study by Manresa (2015). A recent paper by De Paula et al. (2018) extends the model proposed by Manresa (2015) by identifying the structure of the network when information on the social ties is not given with the observable data. Their study provides sufficient conditions for identification when using panel data by introducing a new model based on Adaptive Elastic Net GMM method.

${ }^{6}$ The time distance between each wave is not homogeneous. The first and the second waves are two consecutive years, the third is 6 years later than the second, and the fourth 6 years later than the third. We have used appropriate weights and introduced cohort averages of our dependent variable in our estimations in order to account for this difference in gaps between waves (Cf. Appendix C). 
the instruments are obesity of (two self-nominated) friends' parents, and friends' birth weight; in their study a friend-selection effect might be driving results, rendering the appropriateness of the instrumental variables questionable.

Our study differs from the ones just mentioned in many aspects, which are considered crucial for results to be reliable. First, we believe that mates within a grade represent the best approximation of a potential reference group, as these are individuals who adolescents compare and interact with in their everyday life, especially during meals. Second, looking at the OLS estimations proposed by Christakis and Fowler (2007) and Cohen-Cole and Fletcher (2008), the presence of a lagged dependent (or independent) variable in a social interactions model can lead to substantial biases in the estimation, unless properly addressed. ${ }^{7}$ In this respect, misspecification of the model or of the error structure can lead to very large biases and thus incorrect inference. Our proposed GMM approach conciliates the different positions. Indeed, the econometric framework and estimation strategy used aim at overcoming the limits of the previous works, while relying on plausible hypotheses about past and reference groups. Third, we are able to trace out eating behavioral patterns from adolescence to adulthood. We show that over-weight teenagers may become over-weight adults by picking up wrong habits, mainly through the peer behavior during adolescence. The story seems different for adults who were normal-weight or obese during adolescence: their adult outcome in terms of BMI is a compound effect of past and the behavior of their respective peers at grade level.

The paper is structured as follows. Section two illustrates the main identification issue arising in linear-in-means models of social effects to explain students' BMI as the result of addiction to their own behavior (internal habits) and conformity to outer groups behavior (external habits). The section also shows how to resolve the identification problem in panel data using the lagged endogenous variable as an internal instrument. Section three describes the system GMM estimation strategy employed in the paper. Section four describes the Add Health dataset and presents the main results. Section five concludes.

\section{Identifying Past and Peers Effects in Obesity Behavior: An AR(1) Linear-in-Means Model}

Models of social interactions have been used to streamline the understanding of socioeconomic environments' dynamics. In such environments, markets do not mediate all of agents' choices, which are determined by their preferences as well as by their interactions with others, e.g. their family, their friends, or more generally any socioeconomic group. To our knowledge, most of research in this area of social sciences is based on static economies. In this paper, in line with what is postulated by Özgür, Bisin and Bramoullé (2017), we attempt to studying social interactions in linear dynamic economies. In this framework, the baseline hypotheses stem from assuming that each agent's quadratic preferences are hit by random preference shocks over time and that agents in the same social reference group interact producing a direct externality related to their behavior. Agents' preferences depend also on own previous choice, that in this context basically act as inherent costs to dynamic behavioral changes due to habits. Indeed, many social phenomena are shaped by the effects of preferences for conformity

\footnotetext{
${ }^{7}$ Liu et al.(2006) find evidence of significant bias in estimation relating to the dynamic role of social interactions by making use of simulation techniques.
} 
and are amplified by the presence of limits to reverse choices. This is the case for eating and other risky/addictive behaviors - especially during adolescence -, or for choices which are rendered hardly reversible due to constraints of social and economic nature. Our empirical specification, therefore, mutuates from the literature on individual preferences as being modelled to incorporate internal and external habits: the individual is expected to want to be not too far from where she was yesterday and not too far from others in her reference group. For this reason, we relay on a dynamic Linear-in-Means Model of social interactions to identify the role of addiction to own behavior (internal habits) and conformity to outer groups behavior (external habits) in explaining students' BMI.

Following the general notation of Graham and Hahn (2005), consider $G$ nonoverlapping groups $(g=1, \ldots, G)$ of individuals and $N^{g}$ individuals $\left(i=1, \ldots, N^{g}\right)$ sampled in the $g^{\text {th }}$ group. The following autoregressive model generates the observed data:

$$
\begin{aligned}
& g=1, \ldots, G \\
& y_{t, i g}=a+y_{t-1, i g} \varphi+y_{t, i g}^{e} \beta+\mathbf{x}_{t, g}^{\prime} \gamma+\mathbf{r}_{t, i g}^{\prime} \delta+\varepsilon_{t, i g} \quad \text { where } \quad i=1, ., N^{g} \\
& t=1, \ldots, T
\end{aligned}
$$

The individual-specific terms are defined by a $r \times 1$ vector of observable characteristics, $\mathbf{r}_{t, i g}$, and $\varepsilon_{t, i g}$, a random and unobservable scalar assumed to be independent and identically distributed across individuals. As to group-specific factors, these are divided into a $k \times 1$ vector of predetermined characteristics, $\mathbf{x}_{t, g}$, and the expected average choice in the group, $y_{t, i g}^{e}$. These two terms are conceptually different, the former being interpreted as contextual effects and the latter as an endogenous effect, and those exist under the condition that $\beta$ is non-zero and $\gamma$ has at least a non-zero element. The key effect is exerted by $y_{t, i g}^{e}$, since it creates reciprocal reactions between individual decisions. In practice, the set of individual-specific attributes supposed to be determining individual behavior at time $t$ is assumed to depend on past period choice, $y_{t-1, i g}$. Such an assumption makes sense when not only is choice thought of as being the result of contemporaneous exogenous characteristics, but also of a certain past behavior that could play a role in actual choice. Also, including lagged individual BMI entails implicitly the inclusion of lagged average BMI and lagged contextual variables (cf. Appendix B and B.1 for a Monte Carlo Study of the properties of the model).

Extending the example on peer effects and students' obesity, we use student's body mass index in the previous period, $y_{t-1, i g}$, as an internal instrument to resolve the reflection problem arising in $\mathrm{LMM}^{8}$ since it will be orthogonal to the error term. The use of internal instruments to solve endogeneity problems is advocated for example by Lewbel (1997). Lewbel's idea is that when the endogenous regressor has a skewed distribution, certain transformations of the data, including using lagged endogenous effects, provide a set of valid instruments.

The self-consistency condition in this case is:

$$
y_{t, i g}^{e}=y_{t, g}^{e}=\frac{a+y_{t-1, g} \varphi+\mathbf{x}_{t, g}^{\prime} \gamma+\mathbf{r}_{t, g}^{\prime} \delta}{1-\beta}=\frac{a+\mathbf{x}_{t, g}^{\prime} \gamma}{1-\beta}+\frac{y_{t-1, g} \varphi+\mathbf{r}_{t, g}^{\prime} \delta}{1-\beta} .
$$

The term $y_{t-1, g}$ is the average choice in the group in $t-1$, which enlarges the individual information set among the observable effects. Therefore, even under the assumption

\footnotetext{
${ }^{8}$ See Appendix A for an exposition of the basic reflection problems arising in LMM.
} 
$\mathbf{x}_{t, g}=\mathbf{r}_{t, g}$, there is an additional element, $y_{t-1, g}$, which allows identification. Indeed, the social equilibrium equation is:

$$
y_{t, g}^{e}=\frac{a+\mathbf{x}_{t, g}^{\prime}(\gamma+\delta)}{1-\beta}+\frac{y_{t-1, g} \varphi}{1-\beta} .
$$

Using expected average behavior rather than the realized one is merely due to analytical convenience. This is a reasonable assumption when the behaviors of the rest of group are not directly observable - i.e., in large groups. When it comes to empirical analysis, such an assumption presupposes a restriction on the way individuals form expectations about the average choice in their group. Specifically, expectations are supposed to be consistent with the structure of the choices in the model, or self-consistent. This means that the perceived average choice is equivalent to the mathematical conditional expectation of the average choice, $y_{g}^{e}$, given the information set of each individual. Substituting the social equilibrium into (1) yields:

$$
y_{t, i g}=\frac{a}{1-\beta}+y_{t-1, i g} \varphi+\frac{\beta}{1-\beta} \mathbf{x}_{t, g}^{\prime}(\gamma+\delta)+\frac{\beta \varphi}{1-\beta} y_{t-1, g}+\mathbf{r}_{t, i g}^{\prime} \delta+\varepsilon_{t, i g} .
$$

Clearly, the model is now identified. ${ }^{9}$

The model avoids the linear dependence between $y_{t, g}, \mathbf{x}_{t, g}$ and $\mathbf{r}_{t, g}$ since we have the average action of the group in the previous period, $y_{t-1, g}$, as an additional regressor. This implies that $y_{t, g}$ depends on the entire history of $\mathbf{x}_{t, g}$ and $\mathbf{r}_{t, g}$ resolving the contemporaneous correlation with the same variables. Once the correlation is resolved, we can get an efficient and consistent estimation of all the parameters. Specifically, in the following section we illustrate how to estimate the social interaction parameters in the empirical equation (1).

\section{Estimation}

We consider the following econometric framework:

$$
\begin{aligned}
y_{t, i g} & =y_{t-1, i g} \varphi+y_{t, i g}^{e} \beta+\mathbf{x}_{t, g}^{\prime} \gamma+\mathbf{r}_{t, i g}^{\prime} \delta+e_{t, i g}, \quad|\varphi|<1 \\
e_{t, i g} & =\alpha_{g}+u_{t, i g} \\
u_{t, i g} & =f_{i}+\varepsilon_{t, i g}
\end{aligned}
$$

where we allow for individual-specific effects, captured by $f_{i}$ as well as for group-specific effects, $\alpha_{g} ; \varepsilon_{t, i g}$ is an individual-specific random disturbance. ${ }^{10}$ Notice that the system (5) allows us to decuple $a=\alpha_{g}+f_{i}$ in equation (4). ${ }^{11}$

In order to account for the presence of endogeneity, we assume that:

$$
E\left[\mathbf{h}_{t, i g} \varepsilon_{s, i g}\right] \neq 0, \quad \mathbf{h}_{t, i g}=\left[\mathbf{x}_{t, g}, \mathbf{r}_{t, i g}\right]
$$

\footnotetext{
${ }^{9}$ See Appendix A for further explanation of model identification.

${ }^{10}$ Most of the research on social interaction effects (see De Giorgi et al. 2010 among others) is also accounting for potential correlated (unobservable) effects at the group level, without estimating these effects. Instead our approach is based on the idea that the individual is interacting with the group and that the size of the group varies in absence of any correlated effects as in Lee (2007), Davezies et al., (2009), Bramoullé et al.,(2009).

${ }^{11}$ See Appendix B.
} 
$i=1, \ldots, N^{g}, g=1, \ldots, G$, and $s \leq t$. This assumption allows both for contemporaneous correlation between current disturbances and covariates and feedbacks from past shocks into the current value of the covariates.

We assume that $f_{i}$ and $\varepsilon_{t, i g}$ are independently distributed across individuals and have a familiar error structure in which:

$$
E\left[f_{i}\right]=0, E\left[\varepsilon_{t, i g}\right]=0, E\left[f_{i} \varepsilon_{t, i g}\right]=0 \quad \text { for } t=2, \ldots, T, \quad i=1, \ldots, N^{g}, \quad g=1, \ldots, G
$$

and

$$
E\left[\varepsilon_{t, i g} \varepsilon_{s, i g}\right]=0, \quad \forall t \neq s
$$

In addition, we impose the initial condition

$$
E\left[y_{1, i g} \varepsilon_{t, i g}\right]=0 \text { for } t=2, \ldots, T, i=1, \ldots, N^{g}, g=1, \ldots, G
$$

Conditions (7) and (8) imply the following moment $m=0.5(T-1)(T-2)$ conditions:

$$
E\left[y_{t-s, i g} \Delta \varepsilon_{t, i g}\right]=0 \text { for } t=3, \ldots, T, s \geq 3
$$

First difference GMM can poorly behave when time series are highly persistent, as lagged levels of the series provide only weak instruments for subsequent first differences. In addition, first differencing would lead to lose substantial information from contextual effects, which are somewhat time-invariant. Therefore, we resort to a more efficient GMM estimator that exploits stationarity restrictions. Bond et al. (2001a) show that this system GMM estimator provides more reasonable estimates than first-differenced GMM. ${ }^{12}$ Blundell and Bond (1998) consider the additional assumption that

$$
E\left[f_{i} \Delta y_{2, i g}\right]=0, \text { for } i=1, \ldots, N^{g} \text { and } g=1, \ldots, G
$$

This further assumption implies additional $T-2$ linear moment conditions:

$$
E\left[u_{t, i g} \Delta y_{t-1, i g}\right]=0, \text { for } t=3, \ldots, T, i=1, \ldots, N^{g}, g=1, \ldots, G
$$

These allow us to use lagged first-differences of the series as instruments for the equation in levels, as suggested by Arellano and Bover (1995).

\footnotetext{
${ }^{12}$ We have four waves and around 7,000 valid respondents for each year, therefore we use the ArellanoBond estimator which was designed for small $\mathrm{T}$ large $\mathrm{N}$ panels. The second lag is required, because it is not correlated with the current error term, while the first lag is. This is also shown by the ArellanoBond test for autocorrelation which has a null hypothesis of no autocorrelation and it is applied to the differenced residuals. The test for AR (1) process in first differences usually rejects the null hypothesis (as in our results reported on tables 6-9).
} 


\section{Data and Results}

\subsection{The National Longitudinal Study of Adolescent Health}

The National Longitudinal Study of Adolescent Health (Add Health) ${ }^{13}$ is a (US) nationally representative, school-based survey of youth. The study was designed to determine how family, schools, neighborhoods, and communities and as well as individual characteristics influence health behaviors and therefore health outcomes.

While initially focused on adolescents only, in later phases the study analyzes health and health behaviors during the transition from adolescence into early adulthood. Indeed, in the first years of adulthood the young develop habits, and choose their lifestyle so that future health and well-being are strongly affected by such behaviors. It is therefore possible to study what happens during the transition to adulthood, as well as to explore early behavioral causes of adult chronic diseases.

The survey is made of four waves. In 1994-1995 a random sample of 7 th to 12 th grade students from schools across the country was selected. About 90, 000 young individuals participated by filling out a brief questionnaire at school. Afterwards, at-home interviews with students and their parents were conducted. Students were interviewed again in their homes one year later (1996). School administrators provided information about the school participants attended and existing data were compiled to describe neighborhoods and communities (in both waves $1994-1995$ and 1996). In the last two waves (2001 - 2002; $2007-2008$ ) participants in the first in-home interview were re-interviewed at ages 18 to 26 , and again at ages 24 to 32 .

The survey contains information on demographics, family life and background, school and academic outcomes, and health behaviors (drug use, smoking, pregnancy, etc.). For this research, the desired sample is the one relative to the in-home survey contained in the Restricted Version of the dataset. The reader is cross-referred to Appendix C for further details on design and weighting of data at hand.

\subsection{The Dependent Variable}

Our dependent variable is BMI, constructed using self-reported height and weight. ${ }^{14} \mathrm{BMI}$ is an index of weight-for-height which is age-independent and the same for both sexes. It is computed as weight in kilograms divided by the square of height in metres $\left(\mathrm{kg} / \mathrm{m}^{2}\right)$ and it is standardly used to classify underweight, over-weight and obesity. ${ }^{15}$

\footnotetext{
${ }^{13}$ This research uses data from the Restricted version of Add Health, a project directed by Kathleen Mullan Harris and designed by J. Richard Udry, Peter S. Bearman, and Kathleen Mullan Harris at the University of North Carolina at Chapel Hill, and funded by grant P01-HD31921 from the Eunice Kennedy Shriver National Institute of Child Health and Human Development, with cooperative funding from 23 other federal agencies and foundations. Special acknowledgment is due to Ronald R. Rindfuss and Barbara Entwisle for assistance in the original design. Information on how to obtain the Add Health data files is available on the Add Health website (http://www.cpc.unc.edu/addhealth) and from Harris et al. (2009). No direct support was received from grant P01-HD31921 for this analysis. The usage of the restricted version of the data was approved by Add Health Restricted Use Data Contract Nr: 01091701

${ }^{14}$ We make use of self-reported height and weight because Add Health wave 1 lacks information on measured height and weight. However, it has been shown that BMI computed using self-reported variables is highly correlated with BMI generated using measured height and weight $(r=0.92)$, and correctly classifies $96 \%$ to obesity status (Goodman et al., 2000).

${ }^{15} \mathrm{BMI}$ is not a direct measure of body fatness. However, it parallels changes obtained by direct measures of body fat such as underwater weighing and dual energy x-ray absorptiometry (DXA), therefore it can be considered as a proxy for measures of body fat.
} 
Table 1 shows the international classification of underweight, over-weight and obesity according to BMI, as reported on the WHO studies. ${ }^{16}$

\section{Table 1 about here}

Based on this classification, we constructed a transition matrix for BMI in order to analyse the dynamic behavior of the variable in our sample.

\section{Table 2 about here}

First of all, more than $57 \%$ of individuals have a normal body weight, while the probability of facing a transition to over-weight is about $16 \%$ and to obese about $3.2 \% .{ }^{17}$ Probabilities located on the main diagonal are quite high, meaning that BMI is highly autocorrelated, especially for normal weight and heavily obese people. For instance, $78 \%$ of respondents with normal body weight in $t-1$, will stay in the same category in the next observation window. Such finding strongly corroborates the validity of our empirical specification which includes lagged BMI among the set of regressors, given our hypothesis that past BMI affects current BMI.

\subsection{Descriptive Statistics}

Tables 3 to 5 show the summary statistics of the sample under analysis.

Tables $3-5$ about here

Table 3 displays the descriptive statistics relative to our dependent variable of interest, BMI, and control variables for the whole sample covering all waves. Figure 1 shows that average BMI is close to the threshold between normal weight and over-weight - as predicted by the transition matrix. Having a look at the distribution of BMI (Figure 1) we realize that the modal bins are $\mathrm{BMI}=20-22$ and $\mathrm{BMI}=22-24$, meaning that normal-weight individuals are those for whom frequency is highest. Furthermore, the distribution appears to be right-skewed, signalling a majority of over-weight and obese individuals in the sample observed. Household income levels (Figure 2) are in line with those reported by the US Census Bureau.

Concerning the sample composition of some characteristics of interest, we observe that the proportion of females is slightly larger than males, registering nearly $56 \%$ of counts. Also, the two wider ethnic groups are white and African American, while American Indian and Asian groups have a very small impact on the ethnical composition. The vast majority of individuals is in a good to excellent health status. Finally, the figure on parental education shows a moderate percentage of college graduate, both on the mother and on the father side.

Tables 4 and 5 are informative about variations in average BMI depending on certain characteristics, for both the entire sample and the adolescent subsample (first two waves only) respectively. In both tables the most important figures are the correlation of poorer health statuses with higher average BMI, and the correspondence of lower BMI statuses to higher parental education. Also, those with a household income greater than the median show a lower BMI on average.

\footnotetext{
${ }^{16} \mathrm{http}: / /$ apps.who.int/bmi/index.jsp?introPage =intro.html

${ }^{17}$ Obtained by summing the percentages of all the obese categories, i.e. $2.71 \%, 0.41 \%$ and $0.12 \%$.
} 


\subsection{Reference Groups}

A crucial issue in the analysis of social endogenous effects in eating behavior is the definition of reference groups. Many papers attempting to address the complexities of social interactions in obesity rely on the nomination of adolescents' closest peers or on family history, and this is always subject to selection problems that the authors do not seem to address (e.g., the most important ones, Christakis and Fowler, 2007; Cohen-Cole and Fletcher, 2008; Fowler and Christiakis, 2008; Trogdon et al., 2008). ${ }^{18}$ Besides, it could be restrictive to consider self-nominated friends or family as the only plausible reference group, especially for phenomena like over-weight or obesity which may depend on social norms and acceptance in a broader context. Rather, we believe that mates in the same grade $^{19}$ within the school better fit the potential reference group adolescents compare and interact with. Indeed, interconnections between members of the same grade and school may determine mutual influence through a variety of factors, e.g., food quality and quantity, time spent to exercise, appearance, etc. It is likely that contextual effects (those exerted by environmental factors) on eating behavior are common to schoolmates, and may drive similarities in individual behavior - therefore in their body weight.

Hence, our peer groups correspond to all the individuals belonging to the same grade within a school, meaning that endogenous effects measure the propensity to become over-weight due to a direct interaction within the grade level. Such a choice is consistent with our dynamic analysis of eating behavioral patterns from adolescence to adulthood, mostly because it is believed that what affects the transition of body weight into early adulthood is behavior during adolescence (e.g., inter alia, Kemper et al., 1999; Sun Guo et al., 2002; Kvaavik et al., 2003; Gordon-Larsen et al., 2004) which in turn depends on mates behavior within grades (cf. Section 4.6).

\subsection{Estimation Results}

In this section we report results produced by estimating the system defined in (5). ${ }^{20} \mathrm{~A}$ premise is due at this stage. We make clear to the reader that the lagged dependent variable on the right hand side does not refer to the value of the dependent variable the year before, as the gaps between waves are not homogeneous; rather, that embeds all past history up to the previous wave. In particular, wave one and two are consecutive years registering information on adolescents, wave three is six years later than wave two and includes data on early adults, wave four is again six years later than wave three and contains information on adults. We partly correct for the possible bias due to the uneven gap between waves by including the average BMI by cohort as additional regressors. ${ }^{21}$

\footnotetext{
${ }^{18}$ Cohen-Cole and Fletcher (2008) and Christakis and Fowler (2007) consider the data on obesity status for an individual (in their terminology, an "Ego") at a given point in time and estimate its relationship to the obesity status of a friend ("Alter").

${ }^{19}$ The peer group is formed by clustering grade-school level characteristics.

${ }^{20}$ The Arellano-Bond estimators is available for Stata as proprietor program written by Roodman (2006) (called xtabond2). See http://ideas.repec.org/c/boc/bocode/s435901.html.

${ }^{21}$ The AddHealth design weights do not really account for the unequal space intervals between waves. A recent paper by Millimet et.al. (2015) discusses a way to account for the missing information between uneven waves in dynamic panel models. However, the proposed method does not account for the presence of peer effects. An alternative solution which accounts for the missing information in panels with unequal spacing between waves and peer effects is to include average cohorts effects as an additional regressor in the model estimation, an intuition proposed by McKenzie (2001). By including average cohorts effects, we account for possible cohort unobservable effects induced by uneven wave gaps that are not captured
} 
Our specification allows us to investigate the hypothesis that conformity behaviors related to BMI can spread through peers versus the claim that is merely an individual outcome linked to personal and family history. We also establish for which category of BMI these peer effects may be stronger or weaker.

As pointed by Cohen-Cole and Fletcher (2008), in order to avoid spurious conclusions on the role exerted by group behavior, the estimation should include contextual effects. ${ }^{22}$ In other terms, both individual and group behavior can be affected by exposure to common influences: for example, the opening of a fast food, gym or recreational area near a school could simultaneously affect the weight of all pupils in the same school. Since access to such facilities may be linked to the socio-demographic characteristics of the adolescents in the same school and grade, we include the average values by grade within each school for household income, age, gender, ethnicity and parental education in the estimation. ${ }^{23}$ Therefore, as in Cohen-Cole and Fletcher (2008), we consider a timedependent set of grade-school-specific covariates, $\mathbf{x}_{t, g}$. These represent a much richer set of controls to absorb the average change in social context experienced by all individuals in the sample. They can also be interpreted as grade-school-specific trends which account for environmental factors shared by adolescents in the same grade. Clearly, more environmental confounders may exist which are positively correlated with an individual's BMI. We therefore enrich our instrumental variables set by adding location-specific variables, like community fixed effects. ${ }^{24,25}$ These environmental confounders reflect the social context of the geographical area where the respondents reside and represent a valid set of instruments since they are likely to be correlated with both individual and group BMI but neither with the unobserved individual propensity or tolerance to become over-weight, nor with unobservable effects at the grade-school level. We employ a system GMM estimation which uses the levels equation (4) to obtain a system of two equations: one differenced and one in levels. Additional instruments can be obtained by adding the second equation so that variables in levels can be instrumented with their own lags. This usually increases efficiency. The set of endogenous variables $\left[y_{t-1, i g}, y_{t, g}\right]$ includes lagged individual BMI, $y_{t-1, i g}$, and contemporaneous group BMI, $y_{t, g}$; these are instrumented with GMM style instruments, i.e., third and fourth lags of the endogenous variables $\left[y_{t-3, i g}, y_{t-4, i g}, y_{t-3, g}, y_{t-4, g}\right]$. The exogenous variables chosen as set of standard instruments $\left[\mathbf{r}_{t, i g}, \mathbf{x}_{t, g}, \mathbf{z}_{t}\right]$ include the exogenous controls, $\mathbf{r}_{t, i g}$, their grade-school average contextual effects, $\mathbf{x}_{t, g}=\mathbf{r}_{t, g}$, and additional instruments, $\mathbf{z}_{t}$, characterizing the macroarea where each adolescent lives, the community fixed effects.

by the inclusion of wave dummies. These cohorts are large enough in size (with a minimum of 2,607 to a maximum of 6,366 observations per cohort), avoiding any potential endogeneity isssue.

${ }^{22}$ The paper by Cohen-Cole and Fletcher (2008) argues that previous studies on the spread of obesity (Christakis and Fowler, 2007) do not include a sufficiently broad set of contextual effects to account for a range of hypothesized causes of obesity, therefore overstating the endogenous effect. They also suggest that the significance of a spatially lagged dependent variable involving network dependence and spatial externalities may be misleading, since it may be simply picking up the effects of omitted spatially dependent variables, incorrectly suggesting the existence of a spillover mechanism.

${ }^{23}$ In system GMM, one can include time-invariant regressors, which would disappear in difference GMM. Asymptotically, this does not affect the coefficients estimates for other regressors. This is because all instruments for the levels equation are assumed to be orthogonal to the fixed effects, thus to all timeinvariant variables; in expectation, removing them from the error term does not affect the moments that are the basis for identification.

${ }^{24}$ The definition of neighborhood follows a geographical criterion since these community variables are based on state, county, tract, and block group levels linked to addresses.

${ }^{25}$ Our estimation also accounts of wave effects, through the inclusion of time dummies. 
The first and the second column of Table 6 reports the estimates for the system defined in (5), Model (1) and Model (2). ${ }^{26}$ Results show that current BMI is affected both by past individual decisions and social (peer) behaviors in a significant manner, even after discounting for observable and unobservable concurrent factors. ${ }^{27}$

This result is very much in line with the evidence from the transition probabilities in Table 2 where BMI is highly autocorrelated, especially for heavily obese people. ${ }^{28}$ Looking at the significance of other controls, we find that adolescents belonging to Black ethnic groups have a higher BMI. This result is also in line with other evidence using Add Health data showing that lower socioeconomic status and minority population groups have less access to physical activity facilities, which in turn is associated with decreased physical activity and increased over-weight (Gordon-Larsen et al., 2006). We also find that increases in BMI are less widespread among adolescents whose mother and father gained a college education. There are different channels through which parental education can affect their children's health. Education might have a direct impact on child health because it helps parents to make better health investments for themselves and their children. Alternatively, education can affect child health indirectly. An increased level of education can give access to more skilled work with higher earnings and these resources could be used to invest in health (Case et al., 2002; Lindeboom et al. (2009). We also estimate a model (Model 2) omitting the health dummies and their group averages among the set of regressors. This exclusion has no significant effect of amplifying the impact of lagged individual BMI on individual BMI and to downsize the effect of average BMI. We therefore opt for Model (1) which includes also the health dummy variable among the set of regressors since the significance of lagged individual BMI may simply pick up an omitted variable problem. Note that the potential endogeneity of the health variables is controlled by the use of lagged endogenous instruments in the system GMM estimation. Model (1) also shows that the increase in BMI is positively correlated with income, age and gender (varying more positively for men). The estimation of the full sample in Table 6 is robust to the inclusion of average contextual effects and average BMI in the cohorts as well as additional instruments like community (area) fixed effects. ${ }^{29}$

\subsection{Explaining the Role of Past and Peers in Obesity Behavior}

In this section we want to assess how much past and peers influence the behavior of adults who were normal-weight, over-weight and obese adolescents. ${ }^{30}$

\footnotetext{
${ }^{26}$ We use a robust standard errors estimation where the standard covariance matrix is robust to panel-specific autocorrelation and heteroskedasticity. We also bootstrap the standard error and find no difference with the robust standard errors. The results are available on request.

${ }^{27}$ Our data and theoretical set up do not allow us to calculate direct, indirect and total effects as defined in the spatial econometrics literature (see, for example, Elhorst (2014) and LeSage and Pace (2009)). However, our recursive structure allows us to identify the impact that a change in $y_{t-1, i g}$ has on $y_{t, i_{g}}$ by netting it out from the total average effect, $y_{t, g}$. In this recursive structure the coefficient $\beta$ is therefore approximating the indirect effect on individual behavior, $y_{t, i_{g}}$, that arises as a response to the adjustment of others, $y_{t, i_{g}}$, when a change in individual behavior in the previous period, $y_{t-1, i g}$, takes place.

${ }^{28}$ In Appendix D1 we conduct a falsification test for height based on the paper by Cohen and Fletcher (2008) and we find that height is highly correlated with the past, whereas the size of the average peer effect is relatively small.

${ }^{29}$ In all cases the Hansen J-test does not reject the null hypotheses of over-identifying restrictions.

${ }^{30}$ Specifically, we focus on the International Classification of Weight according to the WHO, as reported in Table 1. In Appendix D2 and D3 we provide a regression analysis for BMI adjusted for age and gender
} 
We note from Table 2 that BMI is highly autocorrelated, especially for normal-weight and heavily obese people. In this instance, personal history and personality traits may dominate upon the influence of the reference group. We therefore estimate model (5) for each BMI category, paying attention to endogenous sample selection arising from selecting categories based on the dependent variable. Hence, we split the sample according to the BMI status in wave 1 and keep individuals in the same strata. This allows us to clearly understand how behaviors during adolescence contribute to adult outcomes. The results for normal, over-weight and obese adolescents are reported in Tables 7, 8 and 9 respectively. First, we find that personal history (lagged BMI) matters for all individuals who were normal, over-weight and obese adolescents; however, normal-weight and obese individuals seem to be affected both by past and peer reference group behavior, with the past exhibiting a stronger effect than their peers. For those who were over-weight adolescents, instead, the effect exerted by social ties is slightly higher. We interpret these outcomes as very informative since the over-weight status can be seen as the transition to obesity. Thus, policies aiming to prevent the spread of obesity may target classes where the presence of over-weight adolescences is relatively higher. Table 7 (Model 1) shows that individual behavior is dominated not only by their past behavior but also by the influence of peers for the sample of individuals who were normal-weight when teenagers. Results show that normal-weight adolescents tend to develop social behavioral pattern in eating, perhaps related to social ties (e.g., Falkner at al, 2001; Chen and Brown, 2005).

Table 8 shows a different behavior for individuals who were over-weight during their adolescence: an increase in average BMI leads to an increase on in current BMI (Model 1) but with a higher magnitude than past behavior. As stressed by Christakis and Fowler (2007), having over-weight or obese school contacts might change a person's tolerance for gaining weight or might influence his or her adoption of specific behaviors (e.g., smoking, eating, and exercising). The fact that adolescents' appearance and behaviors are influenced by the appearance and behaviors of those around them suggests that weight gain in one person might influence weight gain in others. In addition to such strictly social effects, it is plausible that physiological imitation might occur (Fogassi et al., 2005); areas of the brain that correspond to actions such as eating food may be stimulated if these actions are observed in others and this possibility is higher within restricted social environments, such as classes, where individuals spend most of their time. For obese adolescents the story is similar to the normal-weight individuals even though the influence of past is higher. This means that obese adolescents have a higher tendency to remain future obese adults through wrong habits picked up or influenced by their past behavior.

\section{Conclusions}

Personal and family history, the impact of the social context where each individual lives as well as endogenous effects induced by interactions with peer groups are all possible determinants of eating and body-weight related behavior. One of the econometric challenges is to identify the separate impact of the endogenous and contextual effects, and to break the so called "reflection problem" (Manski, 1993). The dynamic linear-in-means model proposed in the paper allows us to estimate all social effects and to control for individual- and group-specific unobservable effects, by exploiting stationarity restrictions

(zBMI). 
of a system GMM estimator.

Our results show that individuals tend to become over-weight also due to social (peer) effects, even properly accounting for contextual effects. In particular, peer behavior seems to explain a relevant part of variation in body mass index of all individuals in the sample. Individuals who were normal-weight and obese during adolescence are influenced both by past behavior and by average behavior in their reference group. For over-weight adolescents, instead, peer effects impact more on current weight status. Such peer effects are of obvious policy significance, though rarely taken into account by policy makers or even by entities with a collective perspective. The implication is that group-level interventions may be more successful and more efficient than individual interventions, as social interactions take place. This means that clinical and policy interventions may be more cost-effective than policy-makers have previously supposed, as we are facing a health problem characterized by social forces. Public health policy makers should implement urgent and targeted actions for preventing this epidemic to spread further.

Despite being able to identify peer groups at the level of grade-mates, data used in our study have some limitations. First, the longitudinal analysis is conducted in a panel dataset with non-homogeneous gaps relative to adolescents who become adults, to which we obviate by including cohort effects and thus possibly minimizing the statistical errors. Second, friends outside of school and romantic partners are not captured. Third, we do not account for a change of their reference group once the adolescents become adult but hypothesize that future friends are not too dissimilar from past ones assuming a behavioral "trap" which is binding individuals' future choices. Future research is needed to better understand the mechanisms behind the influence of peers on weight. Several candidates exist, such as peer influence on weight loss attempts, physical activity, and perceptions of own body weight. The causal mechanisms should also be consistent with effects of higher moment of the BMI distribution. Knowledge about the source of peer influence on weight and the size of any social multipliers will improve implementation and evaluation of policies aimed at reducing over-weight or obesity in adolescence, hence in adulthood. 


\section{References}

Anderson, T.W., and Hsiao, C. (1982). "Formulation and estimation of dynamic models using panel data." Journal of Econometrics, 18: 47-82.

Andajani-Sutjahjo, S., Ball K., Warren, N., Inglis V. and Crawford D. (2004). "Perceived personal, social and environmental barriers to weight maintenance among young women: A community survey." International Journal of behavioral Nutrition and Physical Activity, 1 - 15.

Andreyeva, T., Kelly, I.R., Harris, J., (2011). "Exposure to food advertising on television: associations with children's fast food and soft drink consumption and obesity." Economics and Human Biology 9(3): 221 - 233.

Arellano, M., and Bond, S. (1991). "Some tests of specification for panel data: Monte Carlo evidence and an application to employment equations." Review of Economic Studies 58: 277-97.

Arellano, M., and Bond, S. (1998). "Dynamic Panel data estimation using DPD98 for Gauss: A guide for users."

Arellano, M., and Bover, O. (1995). "Another look at the instrumental variables estimation of error components models." Journal of Econometrics 68: 29-51.

Baum, C., Schaffer, M., and Stillman, S. (2003). "Instrumental variables and GMM: Estimation and testing." Stata Journal 3(1): $1-31$.

Beck, T., and Levine, R. (2004). "Stock markets, banks, and growth: Panel evidence." Journal of Banking and Finance, 28(3): 423-42.

Bénabou, R. (1993). "Workings of a city: Location, education, and production." Quarterly Journal of Economics, CVIII, 619-652.

Bernheim, D. (1994). "A theory of conformity." Journal of Political Economy, 102: $841-877$.

Blundell, R., and Bond, S. (1998). "Initial conditions and moment restrictions in dynamic panel data models." Journal of Econometrics 87: 115-143.

Bond, S., Hoeffler, A., and Temple, J. (2001a). "GMM estimation of empirical growth models." Economics Papers 2001-W21, Economics Group, Nuffield College, University of Oxford.

Bond, S., Bowsher, C., and Windmeijer, F. (2001b): "Criterion-based inference for GMM in autoregressive panel data models." Economics Letters, 73(3): $379-388$.

Bond, S. (2002). "Dynamic panel data models: A guide to micro data methods and practice." Working Paper 09/02. Institute for Fiscal Studies. London.

Brock, W. A., and Durlauf, S. N. (2001). "Discrete choice with social interactions." Review of Economic Studies, 68(2), 235 - 260.

Brown, B. (1990). "Peer groups and peer cultures." in At the Threshold, ed. by S. Feldman, and G. Elliott, Cambridge, MA. Harvard University Press.

Brown, B., Clasen, D., and Eicher, S. (1986). "Perceptions of peer pressure, peer conformity dispositions, and self-reported behavior among adolescents." Developmental Psychology, 22(4): $521-530$

Bramoullé, Y., Djebbari, H., and Fortin, B. (2009). "Identification of peer effects through social networks." Journal of Econometrics, 150(1): 41-55.

Burke, M. A., and Heiland, F. (2007). "Social dynamics of obesity." ,Economic Inquiry, 45, 571-591.

Calvo-Armengol, A., Patacchini, E., Zenou, Y., (2009). "Peer Effects and Social Networks in Education." Review of Economic Studies, 76, 1239 - 1267. 
Case, A., M. Lubotsky and C. Paxson (2002). "Economic Status and Health in Childhood: The Origins of the Gradient." American Economic Review, 92: 1308 - 1334.

Chen, E.Y. and Brown, M. (2005). "Obesity stigma in sexual relationships." Obesity Research, 13(8): $1393-7$.

Christakis N. A., and Fowler, J. (2007). "The spread of obesity in a large social network over 32 years." The New England Journal of Medicine, 357: 370 - 379.

Cohen-Cole, E. (2006). "Multiple groups identification in the linear-in-means model." Economic Letters, 92(2): 157-162.

Cohen-Cole, E., and Fletcher, J. (2008). "Is obesity contagious? Social networks VS. environmental factors in the obesity epidemic." Journal of Health Economics, 27(5): $1382-1387$.

Cohen-Cole, E., and Fletcher, J. (2008). "Detecting implausible social network effects in acne, height, and headaches: longitudinal analysis." British Medical Journal, 3372533.

Crawford, D., and Ball, K. (2002). "Behavioral determinants of the obesity epidemic." Asia Pacific Journal of Clinical Nutrition, 11(Suppl 8): S718 - 721.

Davezies, L., D'Haultfoeuille, X., and Fougre, D. (2009). "Identification of peer effects using group size variation." The Econometrics Journal, 12(3), 397-413.

De Giorgi, G., Pellizzari, M., and Redaelli, S. (2010): "Identification of social interactions through partially overlapping peer groups." American Economic Journal: Applied Economics, 2(2): $241-75$.

De Paula A, Rasul I., and Souza P.,(2018) "Recovering Social Networks from Panel Data: Identification, Simulations and an Application." HCEO WP 2018-013.

Falkner N.H., Neumark-Sztainer, D., Story, M., Jeffery, R.W., Beuhring, T. and Resnick, M.D. (2001). "Social, educational, and psychological correlates of weight status in adolescents." Obesity Research, 9(1):32 - 42.

Fogassi, L., Ferrari, P.F., Gesierich. B., Rozzi, S., Chersi, F., Rizzolatti, G. (2005). "Parietal lobe: from action organization to intention understanding." Science, 308: $662-7$.

Fortin, B. and Yazbeck M. (2011). "Peer Effects, Fast Food Consumption and Adolescent Weight Gain." Centre Interuniversitaire sur le Risque, les Politiques Èconomiques et l'Emploi, Cahier de recherche/Working Paper $11-03$.

Fowler, J., and Christakis, N. A. (2008). "Estimating peer effects on health in social networks; A response to Cohen-Cole and Fletcher; and Trogdon, Nonnemaker, and Pail." Journal of Health Economics, 27, 1400 - 1405.

Goodman, E., Hinden, B. R., and Khandelwal, S. (2000). "Accuracy of teen and parental reports of obesity and body mass index." Pediatrics, 106: $52-58$.

Gordon-Larsen, P., Adair, L.S., Nelson, M.C., and Popkin, B.M. (2004). "Fiveyear obesity incidence in the transition period between adolescence and adulthood: the National Longitudinal Study of Adolescent Health." American Journal of Clinical Nutrition, 80(3): $569-575$.

Gordon-Larsen, P., Nelson M.C., Page P., et al. (2006). "Inequality in the built environment underlies key health disparities in physical activity and obesity." Pediatrics, 117: $417-24$.

Graham, B.S., Hahn, J. (2005). "Identification and estimation of the linear-in-means model of social interactions." Economics Letters, 88: $1-6$.

Gwozdz, Wencke, et al. (2015). "Peer effects on obesity in a sample of European children." Economics \& Human Biology, 18, 139 - 152.

Harris, K.M., Halpern, C.T., Whitsel, E., Hussey, J., Tabor, J., Entzel, P., and Udry, 
J.R. (2009). "The National Longitudinal Study of Adolescent Health:Research Design.", website: http://www.cpc.unc.edu/projects/addhealth/design.

Harris, K. M. (2011). "Design Features of Add Health" Carolina Population Center, website: www.cpc.unc.edu/projects/addhealth/data/guides/.

Elhorst, J. P. (2014). "Spatial Econometrics: From Cross-Sectional Data to Spatial Panels" Springer Briefs in Regional Science, Springer Berlin Heidelberg, New York.

Kandori, M. (1992). "Social norms and community enforcement." Review of Economic Studies, 59: $63-80$.

Kemper, H.C.G., Post, G.B., Twisk, J.W.R., and van Mechelen, W. (1999). "Lifestyle and obesity in adolescence and young adulthood: Results from the Amsterdam Growth And Health Longitudinal Study (AGAHLS)." International Journal of Obesity, 23(3): s34-s40.

Kvaavik, E., Tell, G.S., and Klepp, K. (2003). "Predictors and Tracking of Body Mass Index From Adolescence Into Adulthood. Follow-up of 18 to 20 Years in the Oslo Youth Study." Arch Pediatr Adolesc Med, 157:1212 - 1218.

Lee, L. F. (2007). "Identification and estimation of econometric models with group interactions, contextual factors and fixed effects." Journal of Econometrics 140, 333-74.

LeSage, J. and Pace, R. K. (2009). Introduction to Spatial Econometrics (Statistics: A Series of Textbooks and Monographs), Chapman and Hall/CRC, London.

Lewbel, A. (1997). "Constructing Instruments for Regressions with Measurement Error when no Additional Data are Available with an Application to Patents and RD." Econometrica, 65(5): $1201-1214$.

Lindeboom M., Nozal A. L. and van der Klaauw, B. (2009). "Parental education and child health: Evidence from a schooling reform.", Journal of Health Economics, 28(1): $109-131$.

Manski, C. F. (1993). "Identification of endogenous social effects: The reflection problem." Review of Economic Studies, 60(3): 531 - 542.

Manski, C. F.(2000). "Economic analysis of social interactions." Journal of Economic Perspectives, 14(3): $115-136$.

Manresa, E. (2015). "Estimating the Structure of Social Interactions Using Panel Data." mimeo Working Paper.

McKenzie, D, (2001). "Estimation of AR(1) models with unequally spaced pseudopanels." Econometrics Journal 4,: $89-108$.

Millimet Daniel L. and McDonough Ian K. (2017). "Dynamic Panel Data Models With Irregular Spacing: With an Application to Early Childhood Development." Journal of Applied Econometrics. 32(4); 725 - 743.

Moffitt, R. A. (2001). "Policy interventions, low-level equilibria, and social interactions. " in S. N. Durlauf \& H. P. Young (Eds.), Social dynamics, pp. 45-82.

Özgür, O., Bisin, A., Bramoulle, Y. (2017): "Dynamic Linear Economies with Social Interactions." mimeo Working Paper.

Philipson, T. (2001). "The world-wide growth in obesity: an economic research agenda." Health Economics, 10(1): $1-7$.

Roodman, D. (2006). "How to do xtabond2: An introduction to Difference and System GMM in Stata. " Center for Global Development, Working Paper Number 103.

Sun Guo, S., Wu, W., Chumlea, W.C., and Roche, A.F. (2002). "Predicting over-weight and obesity in adulthood from body mass index values in childhood and adolescence." American Journal of Clinical Nutrition, 76(3):653 - 658 . 
Trogdon, J., Nonnemaker, J., and Pail, J. (2008). "Peer effects in adolescent overweight." Journal of Health Economics, 27, 1388-1399.

Tourangeau, R. and Shin, H. (1999). "National Longitudinal Study of Adolescent health: Grand Sample Weights." National Opinion Research Center and Carolina Population Center. website: http://www.cpc.unc.edu/projects/addhealth/.

Verdier, V. (2015). "Identification and Estimation of Peer Effects with Panel Data." mimeo Working Paper.

Yakusheva, O., Kapinos, K., Weiss, M. (2011). "Peer effects and the Freshman 15: Evidence from a natural experiment." Economics \& Human Biology, 9(2), 119 - 132. 
Table 1: International Classification of Weight According to BMI

\begin{tabular}{lll} 
Classification & Category & BMI (Principal Cut-off Points) \\
\hline Underweight & 1 & $<18.50$ \\
Normal Range & 2 & $18.50-24.99$ \\
Overweight (Pre-Obese) & 3 & $25.00-29.99$ \\
Obese Class I & 4 & $30.00-34.99$ \\
Obese Class II & 5 & $35.00-39.99$ \\
Obese Class III & 6 & $\geq 40$ \\
\hline
\end{tabular}

Note. Source: Adapted from WHO, 1995, WHO, 2000 and WHO 2004.

Table 2: Transition matrix of BMI categories

\begin{tabular}{|c|c|c|c|c|c|c|c|c|}
\hline & & BMI & & & & & & \\
\hline & & 1 & 2 & 3 & 4 & 5 & 6 & Total \\
\hline & 1 & 43.57 & 54.90 & 1.31 & 0.16 & 0.05 & 0.00 & 100 \\
\hline & 2 & 2.20 & 77.80 & 16.63 & 2.71 & 0.41 & 0.12 & 100 \\
\hline $\mathrm{BMI}$ in $t-1$ & 3 & 0.31 & 13.55 & 55.74 & 24.96 & 4.64 & 1.07 & 100 \\
\hline & 4 & 0.00 & 2.06 & 12.65 & 41.76 & 28.04 & 14.90 & 100 \\
\hline & 5 & 0.00 & 0.94 & 4.68 & 15.22 & 28.57 & 50.59 & 100 \\
\hline & 6 & 0.29 & 0.29 & 2.02 & 4.03 & 13.26 & 80.12 & 100 \\
\hline & Total & 6.31 & 57.48 & 18.82 & 9.06 & 3.98 & 4.35 & 100 \\
\hline
\end{tabular}

Note. Categories defined as in Table 1

Table 3: Summary Statistics (Waves I-IV, total sample)

\begin{tabular}{|c|c|c|c|c|}
\hline Variable & Definition & Mean & S.D. & No. Observations \\
\hline BMI & weight $(\mathrm{kg}) /$ height $^{2}(\mathrm{~m})$ & 24.96 & 6.10 & 28,963 \\
\hline Household Income & Total income before taxes & $54,406.31$ & $46,098.65$ & 28,619 \\
\hline Median of Household Income & 45,000 & & & \\
\hline 1st percentile & 765 & & & \\
\hline 99th percentile & 170,000 & & & \\
\hline Ethnicity (\%) & Race as observed by interviewer & & & 28,942 \\
\hline White & & 0.66 & 0.47 & \\
\hline Black & African American & 0.22 & 0.41 & \\
\hline American Indian & Native American. & 0.01 & 0.10 & \\
\hline Asian & & 0.06 & 0.25 & \\
\hline Other & & 0.02 & 0.16 & \\
\hline Self-reported Health (\%) & & & & 28,966 \\
\hline Excellent & & 0.27 & 0.27 & \\
\hline Very Good & & 0.39 & 0.44 & \\
\hline Good & & 0.25 & 0.43 & \\
\hline Fair & & 0.06 & 0.23 & \\
\hline Poor & & 0.29 & 0.45 & \\
\hline Age & Age from birth & 20.79 & 5.39 & 28,964 \\
\hline Gender (\%) & Proportion of females & 55.66 & 49.67 & 28,967 \\
\hline Mother Education (\% ) & Proportion of college graduate (or certified 4 years in college) & 29.36 & 45.54 & 27,799 \\
\hline Father Education (\%) & Proportion of college graduate (or certified 4 years in college) & 32.23 & 46.73 & 27,799 \\
\hline
\end{tabular}


Table 4: Average BMI by Subsample (Waves I-IV, total sample)

\begin{tabular}{lcr}
\hline Variable & Mean & SD \\
\hline BMI if Male & 25.07 & 5.67 \\
BMI if Female & 24.88 & 6.43 \\
BMI if White & 24.77 & 5.94 \\
BMI if Black & 26.02 & 6.59 \\
BMI if American Indian & 27.00 & 7.42 \\
BMI if Asian & 23.73 & 5.68 \\
BMI if Other & 23.40 & 4.50 \\
BMI if Mother went to college & 24.33 & 5.81 \\
BMI if Father went to college & 23.80 & 5.36 \\
BMI if Excellent health & 23.28 & 4.48 \\
BMI if Very good health & 24.43 & 5.51 \\
BMI if Good health & 26.61 & 6.92 \\
BMI if Fair health & 28.74 & 8.18 \\
BMI if Poor health & 31.21 & 10.02 \\
BMI if Household income>Median & 24.72 & 5.84 \\
BMI if Household income<Median & 25.22 & 6.36 \\
\hline
\end{tabular}

Total Sample Size: 28,967 person-year observations

Table 5: Average BMI by Subsample (Waves I-II, adolescent sample)

\begin{tabular}{lrr}
\hline Variable & Mean & SD \\
\hline BMI & 22.81 & 4.79 \\
BMI if Male & 22.92 & 4.66 \\
BMI if Female & 22.73 & 4.89 \\
BMI if White & 22.55 & 4.62 \\
BMI if Black & 23.67 & 5.16 \\
BMI if American Indian & 24.83 & 6.31 \\
BMI if Asian & 21.82 & 4.57 \\
BMI if Other & 23.29 & 4.50 \\
BMI if Mother went to college & 22.31 & 4.48 \\
BMI if Father went to college & 21.92 & 4.22 \\
BMI if Excellent health & 21.69 & 3.66 \\
BMI if Very good health & 22.41 & 4.24 \\
BMI if Good health & 23.96 & 5.53 \\
BMI if Fair health & 25.96 & 6.74 \\
BMI if Poor health & 26.50 & 7.47 \\
BMI if Household income>Median & 22.43 & 4.50 \\
BMI if Household income $<$ Median & 23.16 & 5.02 \\
BMI if Smoked at least 1 cigarette daily for 30 days & 23.01 & 4.94 \\
BMI if Smokers in household & 23.01 & 4.98 \\
BMI if Own decision in diet & 22.85 & 4.74 \\
BMI if Have dinner with parents frequently & 23.17 & 5.11 \\
\hline Total Sample Size: 13,341 person-year observations & &
\end{tabular}




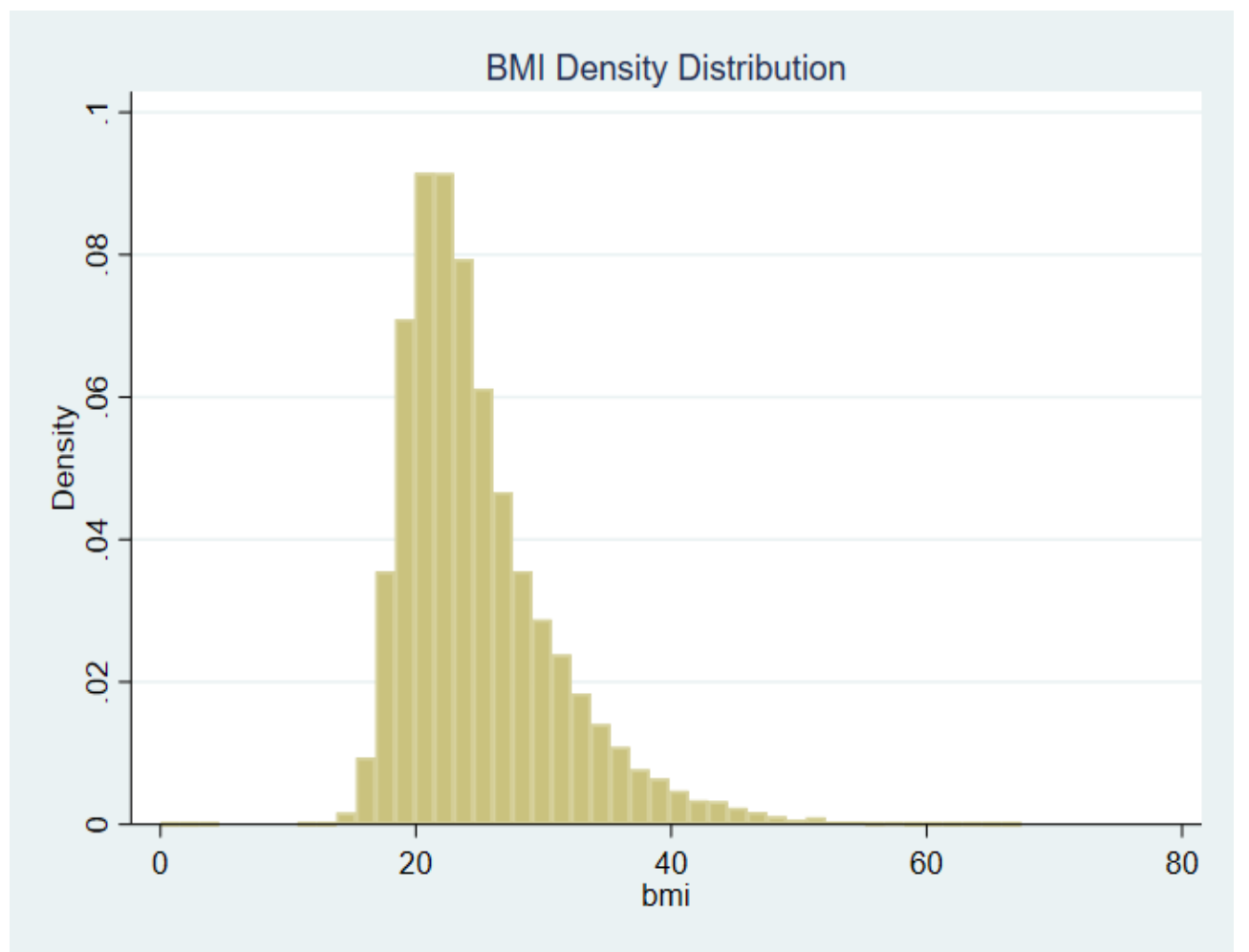

Figure 1: BMI index density Distribution

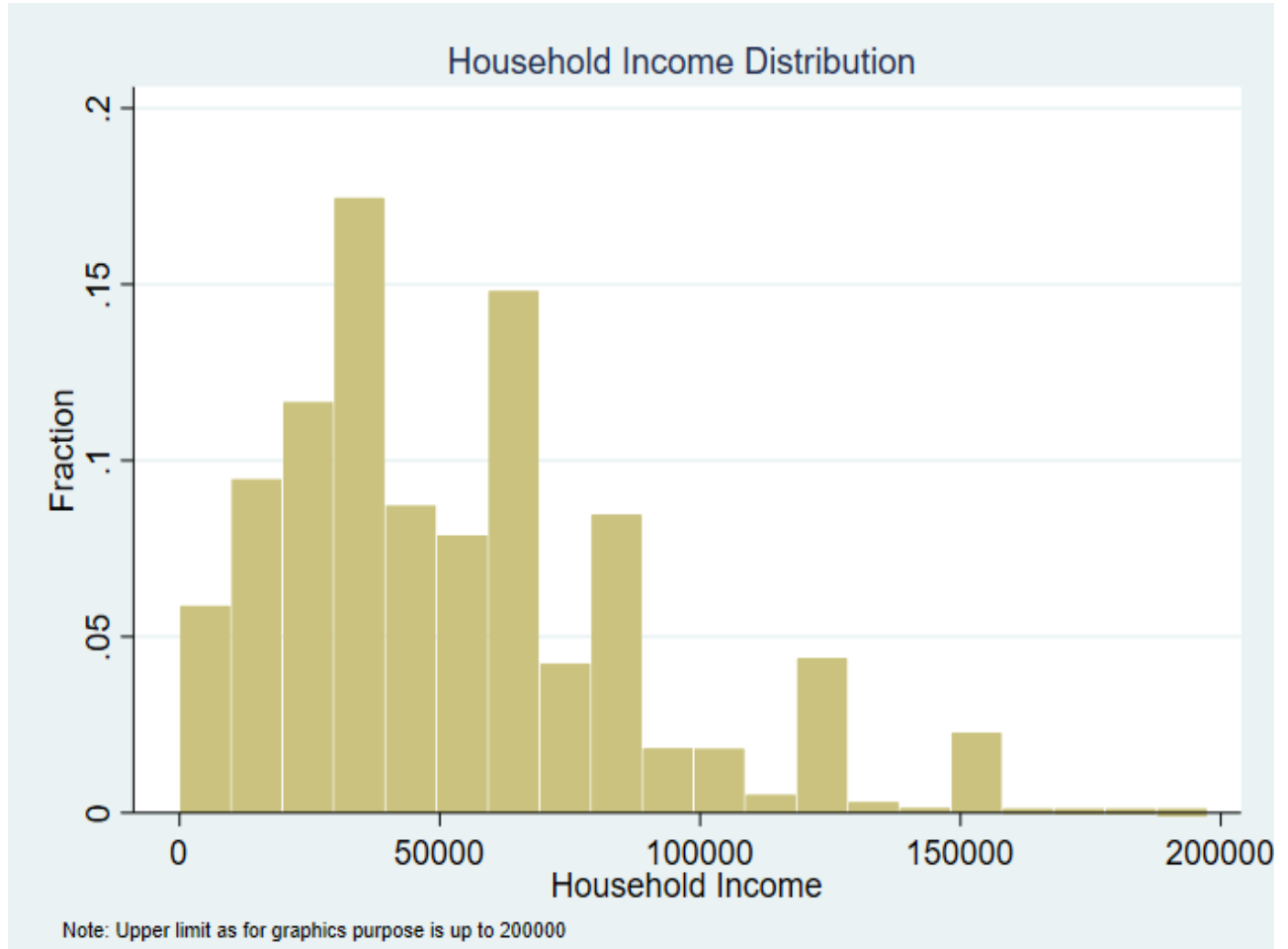

Figure 2: Household Income Frequency Distribution 
Table 6: Estimates using full sample

\begin{tabular}{|c|c|c|c|c|}
\hline Dependent Variable: $\ln (B M I)_{t}$ & \multicolumn{2}{|l|}{ Model 1} & \multicolumn{2}{|l|}{ Model 2} \\
\hline Variables & Coeff. & $\mathrm{SE}$ & Coeff. & $\mathrm{SE}$ \\
\hline $\ln (B M I)_{t-1}$ & $0.611^{* * *}$ & 0.014 & $0.621^{* * *}$ & $\overline{0.014}$ \\
\hline Average $\ln (B M I)_{t}$ & $0.414^{* * *}$ & 0.021 & $0.405^{* * *}$ & 0.021 \\
\hline Household Income & $0.003^{*}$ & 0.002 & $0.003^{*}$ & 0.002 \\
\hline Age & $0.011^{*}$ & 0.005 & $0.010^{*}$ & 0.005 \\
\hline Woman & $-0.012^{* * *}$ & 0.003 & $-0.010^{* * *}$ & 0.003 \\
\hline Ethnic Group: White & 0.17 & 0.012 & 0.018 & 0.012 \\
\hline Ethnic Group: Black & $0.046^{* * *}$ & 0.013 & $0.047^{* * *}$ & 0.014 \\
\hline Ethnic Group: American Indian & 0.008 & 0.020 & 0.010 & 0.020 \\
\hline Ethnic Group: Asian & -0.016 & 0.014 & -0.015 & 0.014 \\
\hline Maternal Education (College) & -0.006 & 0.004 & $-0.007^{*}$ & 0.004 \\
\hline Paternal Education (College) & $-0.014^{* * *}$ & 0.004 & $-0.015^{* * *}$ & 0.004 \\
\hline Health Status (Excellent to Fair) & $-0.029^{* * *}$ & 0.004 & & \\
\hline Contextual Average Effects & $\checkmark$ & & $\checkmark$ & \\
\hline Average Cohorts BMI & $\checkmark$ & & $\checkmark$ & \\
\hline Wave Fixed Effects & $\checkmark$ & & $\checkmark$ & \\
\hline Observations & 15,064 & & 15,064 & \\
\hline Number of individuals & 5,046 & & 5,046 & \\
\hline Number of Instruments & 114 & & 108 & \\
\hline Arellano-Bond Test for AR(1): $\operatorname{Pr}>z$ & 0.000 & & 0.000 & \\
\hline Hansen test of overid. restrictions: $\operatorname{Pr}>\chi^{2}$ & 0.937 & & 0.945 & \\
\hline
\end{tabular}

Robust standard errors in parentheses; ${ }^{* * *} p<0.01,{ }^{* *} p<0.05,{ }^{*} p<0.1$

Notes

1) Average levels are calculated at Grade level within Schools

2) Model 1: Full Observations considering Health as Exogenous

3) Model 2: Full Observations excluding Health

4) Community Fixed Effects included as Additional Instruments 
Table 7: Estimates for individuals who are normal-weight during adolescence

\begin{tabular}{lcccc}
\hline Dependent Variable: $\ln (B M I)_{t}$ & Model 1 & \multicolumn{2}{c}{ Model 2 } \\
\hline Variables & Coeff. & SE & Coeff. & SE \\
\hline $\ln (B M I)_{t-1}$ & $0.389^{* * *}$ & 0.031 & $0.396^{* * *}$ & 0.031 \\
Average $\ln (B M I)_{t}$ & $0.398^{* * *}$ & 0.028 & $0.395^{* * *}$ & 0.028 \\
Household Income & 0.003 & 0.002 & 0.003 & 0.002 \\
Age & 0.004 & 0.006 & 0.004 & 0.006 \\
Woman & $-0.017^{* * *}$ & 0.005 & $-0.015^{* * *}$ & 0.005 \\
Ethnic Group: White & 0.019 & 0.012 & 0.020 & 0.012 \\
Ethnic Group: Black & $0.038^{* * *}$ & 0.014 & $0.041^{* * *}$ & 0.014 \\
Ethnic Group: American Indian & 0.025 & 0.022 & 0.025 & 0.022 \\
Ethnic Group: Asian & -0.012 & 0.015 & -0.011 & 0.015 \\
Maternal Education (College) & -0.003 & 0.006 & -0.003 & 0.006 \\
Paternal Education (College) & $-0.016^{* * *}$ & 0.005 & $-0.018^{* * *}$ & 0.005 \\
Health Status (Excellent to Fair) & $-0.029^{* * *}$ & 0.005 & & $\checkmark$ \\
\hline Contextual Average Effects & $\checkmark$ & & $\checkmark$ & \\
Average Cohorts BMI & $\checkmark$ & & & $\checkmark$ \\
Wave Fixed Effects & $\checkmark$ & & 9,414 & \\
\hline Observations & 9,414 & & & \\
Number of individuals & 3,154 & & 0.000 & \\
Number of Instruments & 178 & & 0.280 & \\
Arellano-Bond Test for AR(1): $\operatorname{Pr}>z$ & 0.000 & & & \\
Hansen test of overid. restrictions: $\operatorname{Pr}>\chi^{2}$ & 0.244 & & & \\
\hline
\end{tabular}

Robust standard errors in parentheses; ${ }^{* * *} p<0.01,{ }^{* *} p<0.05,{ }^{*} p<0.1$

Notes

1) Average levels are calculated at grade level within school

2) Model 1: Full Observations considering Health as Exogenous

3) Model 2: Full Observations excluding Health

4) Community Fixed Effects included as additional Instruments 
Table 8: Estimates for individuals who are over-weight during adolescence

\begin{tabular}{|c|c|c|c|c|}
\hline Dependent Variable: $\ln (B M I)_{t}$ & \multicolumn{2}{|c|}{ Model 1} & \multicolumn{2}{|l|}{ Model 2} \\
\hline Variables & Coeff. & SE & Coeff. & SE \\
\hline $\ln (B M I)_{t-1}$ & $0.328^{* * *}$ & 0.049 & $0.336^{* * *}$ & 0.049 \\
\hline Average $\ln (B M I)_{t}$ & $0.395^{* * *}$ & 0.045 & $0.395^{* * *}$ & 0.044 \\
\hline Household Income & 0.003 & 0.005 & 0.002 & 0.005 \\
\hline Age & -0.020 & 0.014 & -0.022 & 0.011 \\
\hline Woman & $0.021^{*}$ & 0.011 & $0.022^{* *}$ & 0.011 \\
\hline Ethnic Group: White & -0.023 & 0.033 & -0.029 & 0.035 \\
\hline Ethnic Group: Black & -0.011 & 0.036 & -0.015 & 0.037 \\
\hline Ethnic Group: American Indian & -0.034 & 0.043 & -0.030 & 0.045 \\
\hline Ethnic Group: Asian & -0.071 & 0.046 & -0.071 & 0.048 \\
\hline Maternal Education (College) & -0.012 & 0.012 & -0.013 & 0.012 \\
\hline Paternal Education (College) & -0.013 & 0.012 & -0.014 & 0.012 \\
\hline Health Status (Excellent to Fair) & $-0.029^{* * *}$ & 0.009 & & \\
\hline Contextual Average Effects & $\checkmark$ & & $\checkmark$ & \\
\hline Average Cohorts BMI & $\checkmark$ & & $\checkmark$ & \\
\hline Wave Fixed Effects & $\checkmark$ & & $\checkmark$ & \\
\hline Observations & 1,991 & & 1,991 & \\
\hline Number of individuals & 666 & & 666 & \\
\hline Number of Instruments & 108 & & 107 & \\
\hline Arellano-Bond Test for AR(1): $\operatorname{Pr}>z$ & 0.000 & & 0.000 & \\
\hline Hansen test of overid. restrictions: $\operatorname{Pr}>\chi^{2}$ & 0.071 & & 0.086 & \\
\hline
\end{tabular}

Robust standard errors in parentheses; ${ }^{* * *} \mathrm{p}<0.01,{ }^{* *} \mathrm{p}<0.05,{ }^{*} \mathrm{p}<0.1$

Notes

1) Average levels are calculated at grade level within school

2) Model 1: Full Observations considering Health as Exogenous

3) Model 2: Full Observations excluding Health

4) Community Fixed Effects included as additional Instruments 
Table 9: Estimates for individuals who are obese during adolescence

\begin{tabular}{|c|c|c|c|c|}
\hline Dependent Variable: $\ln (B M I)_{t}$ & \multicolumn{2}{|l|}{ Model 1} & \multicolumn{2}{|c|}{ Model 2} \\
\hline Variables & Coeff. & SE & Coeff. & $\mathrm{SE}$ \\
\hline $\ln (B M I)_{t-1}$ & $0.411^{* * *}$ & 0.062 & $0.425^{* * *}$ & $\overline{0.061}$ \\
\hline Average $\ln (B M I)_{t}$ & $0.342^{* * *}$ & 0.064 & $0.327^{* * *}$ & 0.066 \\
\hline Household Income & 0.006 & 0.005 & 0.007 & 0.005 \\
\hline Age & 0.026 & 0.023 & 0.026 & 0.024 \\
\hline Woman & $0.030^{* *}$ & 0.015 & $0.030^{*}$ & 0.015 \\
\hline Ethnic Group: White & 0.032 & 0.040 & 0.046 & 0.041 \\
\hline Ethnic Group: Black & 0.043 & 0.046 & 0.053 & 0.048 \\
\hline Ethnic Group: American Indian & 0.048 & 0.080 & 0.065 & 0.081 \\
\hline Ethnic Group: Asian & 0.020 & 0.048 & 0.035 & 0.049 \\
\hline Maternal Education (College) & 0.007 & 0.019 & 0.007 & 0.020 \\
\hline Paternal Education (College) & $-0.030^{*}$ & 0.017 & $-0.033^{*}$ & 0.017 \\
\hline Health Status (Excellent to Fair) & $-0.039^{* *}$ & 0.012 & & \\
\hline Contextual Average Effects & $\checkmark$ & & $\checkmark$ & \\
\hline Average Cohorts BMI & $\checkmark$ & & $\checkmark$ & \\
\hline Wave Fixed Effects & $\checkmark$ & & $\checkmark$ & \\
\hline Observations & 988 & & 988 & \\
\hline Number of individuals & 331 & & 331 & \\
\hline Number of Instruments & 102 & & 101 & \\
\hline Arellano-Bond Test for AR(1): $\operatorname{Pr}>z$ & 0.000 & & 0.000 & \\
\hline Hansen test of overid. restrictions: $\operatorname{Pr}>\chi^{2}$ & 0.462 & & 0.475 & \\
\hline
\end{tabular}

Robust standard errors in parentheses; ${ }^{* * *} p<0.01,{ }^{* *} p<0.05,{ }^{*} p<0.1$

Notes

1) Average levels are calculated at grade level within school

2) Model 1: Full Observations considering Health as Exogenous

3) Model 2: Full Observations excluding Health

4) Community Fixed Effects included as Additional Instruments 


\section{[FOR ONLINE PUBLICATION] \\ Supplementary Material FOR "Body Mass Index and Social Interactions from Adolescence to Adulthood"}

\section{A The Linear-in-Means Model}

The baseline LMM is conceptually very simple. Usually not derived from any predefined individual decision problem, this model allows individual behavior to linearly depend on some individual-specific characteristics as well as on group-specific factors, which include some group observable characteristics and the expected aggregate behavior of the others in the group. ${ }^{1}$ This makes it easily interpretable as a regression model, and therefore interesting to the econometrician. However, as pointed out by Manski (1993), the LMM suffers from a special kind of identification problem - the so called reflection problem - due to difficulties in disentangling two different group-effects, namely contextual and endogenous effects. Therefore, in such a framework measuring the impact of social interactions is typically challenging. Consider the simple version of the model, where estimation concerns are not yet addressed. Assume to have $G$ non-overlapping, a priori determined groups, each of them made of $N^{g}$ individuals. Individual choice is assumed to be the result of the following process:

$$
y_{i g}=a+y_{i g}^{e} \beta+\mathbf{x}_{g}^{\prime} \gamma+\mathbf{r}_{i g}^{\prime} \delta+\varepsilon_{i g}, \text { where } \begin{gathered}
g=1, \ldots, G \\
i=1, \ldots, N^{g}
\end{gathered} .
$$

The individual-specific terms are defined by a $r \times 1$ vector of observable characteristics, $\mathbf{r}_{i g}$, and $\varepsilon_{i g}$, a random and unobservable scalar assumed to be independent and identically distributed across individuals. As to group-specific factors, these are divided into a $k \times 1$ vector of predetermined characteristics, $\mathbf{x}_{g}$, and the expected average choice in the group, $y_{i g}^{e}$. These two terms are conceptually different, the former being interpreted as contextual effects and the latter as an endogenous effect, and those exist under the condition that $\beta$ is non-zero and $\gamma$ has at least a non-zero element. The key effect is exerted by $y_{i g}^{e}$, since it creates reciprocal reactions between individual decisions.

The information set for $y_{i g}^{e}$ includes values of $r_{i g}$ for other individuals within $i$ 's group, as well as the equilibrium expected choice level that occurs for her group. Individuals are assumed to be unable to observe the choices of others, $y_{-i g}$, or their random payoff terms $\varepsilon_{i g}$. Alternative information assumptions will not affect the qualitative properties of the model. For the LMM, self-consistency amounts to:

$$
y_{i g}^{e}=y_{g}^{e}=\frac{a+\mathbf{x}_{g}^{\prime} \gamma+\mathbf{r}_{g}^{\prime} \delta}{1-\beta}=\frac{a+\mathbf{x}_{g}^{\prime} \gamma}{1-\beta}+\frac{\mathbf{r}_{g}^{\prime} \delta}{1-\beta},
$$

where $\mathbf{r}_{g}$ is the average of $\mathbf{r}_{i g}$ within group $g$.

Notice that such an assumption on the aggregate outcome implies a unique equilibrium: there exists only one expected average choice level that is consistent with the model, given individual and group characteristics. Therefore, equation (2) maps these characteristics into a single $y_{g}^{e}$.

An identification problem in this framework could arise because endogenous and contextual effects may co-move. Indeed, under the self-consistency assumption, the contextual variables determine the endogenous variable, as indicated by condition (2). Given that the identification failure is a consequence of the correlation, by construction, between the endogenous and the contextual effects, Manski (1993) renamed it 'reflection problem', which is not too dissimilar from the basic identification problem in linear regressions with linearly dependent covariates.

\footnotetext{
${ }^{1}$ LMM can be the result of an optimal decision problem framed around agent's choice, as illustrated in Brock and Durlauf (2001).
} 
Manski's original argument is that every contextual effect might be defined as the average of a corresponding individual characteristic. For example, if one controls for student's maternal education one also introduces average (school) maternal education so that $\mathbf{x}_{g}=\mathbf{r}_{g}$. Condition (2) becomes

$$
y_{g}^{e}=\frac{a+\mathbf{x}_{g}^{\prime}(\gamma+\delta)}{1-\beta}
$$

meaning that the regressor $y_{i g}^{e}=y_{g}^{e}$ in (1) is linearly dependent on the regressors $a$ and $\mathbf{x}_{g}$ in (1), so the parameters are not identified. Substituting (3) into (1):

$$
y_{i g}=\frac{a}{1-\beta}+\frac{\beta}{1-\beta} \mathbf{x}_{g}^{\prime}(\gamma+\delta)+\mathbf{r}_{i g}^{\prime} \delta+\varepsilon_{i g}
$$

We can therefore state the following two remarks on the identification of social interaction effects in a LMM:

Remark 1 In the empirical model (1) the set of regressors $\left(1, y_{g}^{e}, \mathbf{x}_{g}, \mathbf{r}_{i g}\right)$ requires the estimation of $2+k+r$ parameters.

Remark 2 Assuming reflection $\mathbf{r}_{g}=\mathbf{x}_{g}$ in the reduced form (4) the set of regressors $\left(1, \mathbf{x}_{g}, \mathbf{r}_{i g}\right)$ allows us to identify $1+k+r$ parameters. Hence, the endogenous effect parameter, $\beta$, remains unidentified.

It is then clear why in the LMM framework identification of parameters is a major challenge. In Section two of the paper we show how to achieve identification of the endogenous effect parameter, $\beta$.

\section{B GMM and Correlated Effects in Dynamic Linear Panel Data Models}

Consider system (5) with correlated effects both at the individual level, $f_{i}$, and group level, $\alpha_{g}$.

$$
\begin{aligned}
y_{t, i g} & =y_{t-1, i g} \varphi+y_{t, i g}^{e} \beta+\mathbf{x}_{t, g}^{\prime} \gamma+\mathbf{r}_{t, i g}^{\prime} \delta+e_{t, i g},|\varphi|<1 \\
e_{t, i g} & =\alpha_{g}+u_{t, i g} \\
u_{t, i g} & =f_{i}+\varepsilon_{t, i g}
\end{aligned}
$$

By recursion we can write (for $t=1, \ldots, T)$ :

$$
\begin{aligned}
y_{t, i g}= & \left(1+\varphi+\ldots+\varphi^{t-1}\right) f_{i}+\left(1+\varphi+\ldots+\varphi^{t-1}\right) \alpha_{g}+\varphi^{t} y_{0, i g}+ \\
& +\left[y_{t, i g}^{e} \beta+y_{t-1, i g}^{e} \beta \varphi+\ldots+y_{1, i g}^{e} \beta \varphi^{t-1}\right] \\
& +\left[\mathbf{x}_{t, g}^{\prime} \gamma+\mathbf{x}_{t-1, g}^{\prime} \gamma \varphi+\ldots+\mathbf{x}_{1, g}^{\prime} \gamma \varphi^{t-1}\right]+ \\
& +\left[\mathbf{r}_{t, i g}^{\prime} \delta+\mathbf{r}_{t-1, i g}^{\prime} \delta \varphi+\ldots+\mathbf{r}_{1, i g}^{\prime} \delta \varphi^{t-1}\right]+ \\
& +\left[\varepsilon_{t, i g}+\varphi \varepsilon_{t-1, i g}+\ldots+\varphi^{t-1} \varepsilon_{1, i g}\right]
\end{aligned}
$$

We can write system (6) in compact form as: 


$$
E\left[y_{t, i g} \mid \mathbf{W}_{i}\right]=\mathbf{W}_{i}^{\prime} \boldsymbol{\Pi}+\eta\left(f_{i}+\alpha_{g}\right)
$$

where $\mathbf{W}_{i}=\left[y_{0, i g}, y_{t, i g}^{e}, \ldots, y_{1, i g}^{e}, \mathbf{x}_{t, g}, \ldots, \mathbf{x}_{1, g}, \mathbf{r}_{t, i g}, \ldots, \mathbf{r}_{1, i g}\right]$. The $\boldsymbol{\Pi}$ matrix is defined in terms of the coefficients of the linear predictors of the dependent variable at each period given all explanatory variables at all periods. Hence, for the individual effect, $f_{i}$, and the group effect, $\alpha_{g}$, we therefore have:

$$
E\left[f_{i}, \alpha_{g} \mid \mathbf{W}_{i}\right]=0
$$

\section{B.1 A Montecarlo Exercise}

We perform a simple simulation exercise in order to detect the finite sample properties of the system GMM estimation of the empirical model (5). The values of the two main coefficients of interest $\varphi$ and $\beta$ are consistent with the values we obtain from our general empirical analysis. Table B.1 summaries all the results for different $T$ values. A GMM estimation generally produces relatively unbiased estimates of $\varphi$ and $\beta$ and small RMEs. Increasing $T$ generally ameliorates these results by reducing the RMSE.

Table B1: Montecarlo simulation for different parameters values

\begin{tabular}{lccc|ccc|ccc}
\hline & \multicolumn{3}{c}{$\mathrm{T}=4$} & \multicolumn{3}{c|}{$\mathrm{T}=10$} & \multicolumn{3}{c}{$\mathrm{T}=20$} \\
\hline Parameters: & Mean & Bias & RMSE & Mean & Bias & RMSE & Mean & Bias & RMSE \\
\hline$\varphi=0.2$ & 0.201 & 0.001 & 0.009 & 0.201 & 0.001 & 0.006 & 0.199 & -0.001 & 0.004 \\
$\beta=0.1$ & 0.102 & 0.002 & 0.091 & 0.098 & -0.002 & 0.056 & 0.097 & -0.002 & 0.032 \\
\hline$\varphi=0.4$ & 0.402 & 0.002 & 0.009 & 0.401 & 0.001 & 0.005 & 0.399 & -0.001 & 0.004 \\
$\beta=0.2$ & 0.202 & 0.002 & 0.090 & 0.198 & -0.002 & 0.056 & 0.197 & -0.003 & 0.032 \\
\hline$\varphi=0.6$ & 0.602 & 0.002 & 0.009 & 0.601 & 0.001 & 0.006 & 0.599 & -0.002 & 0.004 \\
$\beta=0.4$ & 0.403 & 0.003 & 0.091 & 0.398 & -0.002 & 0.056 & 0.599 & -0.001 & 0.004 \\
\hline$\varphi=0.8$ & 0.802 & 0.002 & 0.009 & 0.801 & 0.001 & 0.006 & 0.799 & -0.001 & 0.004 \\
$\beta=0.6$ & 0.602 & 0.002 & 0.091 & 0.598 & -0.002 & 0.056 & 0.597 & -0.003 & 0.032 \\
\hline
\end{tabular}

Notes:

1. The sample size $(N)=14.000$ obs. and groups $(G)=125$

2. 1000 Montecarlo Replications

3. The values of $\varphi$ and $\beta$ are consistent with the Add Health model Estimation

\section{Design Weighting}

The Add Health Study is a US representative, probability-based survey of adolescents in grades 7 through 12 conducted between 1994 and 1995, and extended to 2008 with three in-home interviews. The sample design used to collect the data embeds a certain degree of complexity which should be accounted for. Indeed, failing at considering such complexity may result in biased parameter estimates and incorrect variance estimates. Hence, we corrected for design effects and unequal probability of selection, according to what is suggested in the Add Health user guides. ${ }^{2}$ We exploit the longitudinal feature of the dataset, keeping the strength of its innovative design. With the longitudinal data from adolescence, the third and four in-home interviews allow "researchers to map early trajectories out of adolescence in health, achievement, social

\footnotetext{
${ }^{2}$ http://www.cpc.unc.edu/projects/addhealth/data/guides
} 
relationships, and economic status and to document how adolescent experiences and behaviors are related to decisions, behavior, and health outcomes in the transition to adulthood. The fundamental purpose of this [...] follow-up was to understand how what happens in adolescence is linked to what happens in the transition to adulthood when adolescents begin to negotiate the social world on their own and develop their expectations and goals for their future adult roles." (Harris, 2011). Data have been appropriately weighted to correct their longitudinal format. For details on the Add Health weighting scheme, the reader is cross-referred to Tourangeau and Shin (1999).

\section{Falsification and Robustness tests}

\section{D.1 Falsification Test}

We provide a simple falsification test (see Cohen and Fletcher (2008)) where instead of using BMI as our main dependent variable, we include an alternative continuous time-varying variable, i.e the height of all the respondents, information available in Add Health up to wave 4.

For body height we expect past behavior to exhert the strongest effect and the peer effect to be negligible or absent. We re-estimate our model (5) by including past height as well as average height by grade-school groups. Table D.1, shows that the past accounts for most of the current height in the full sample. The peer effect, even though significant ${ }^{3}$, is very small compared to the past. ${ }^{4}$

Table D1: Falsification Test on Height: Estimates using full sample

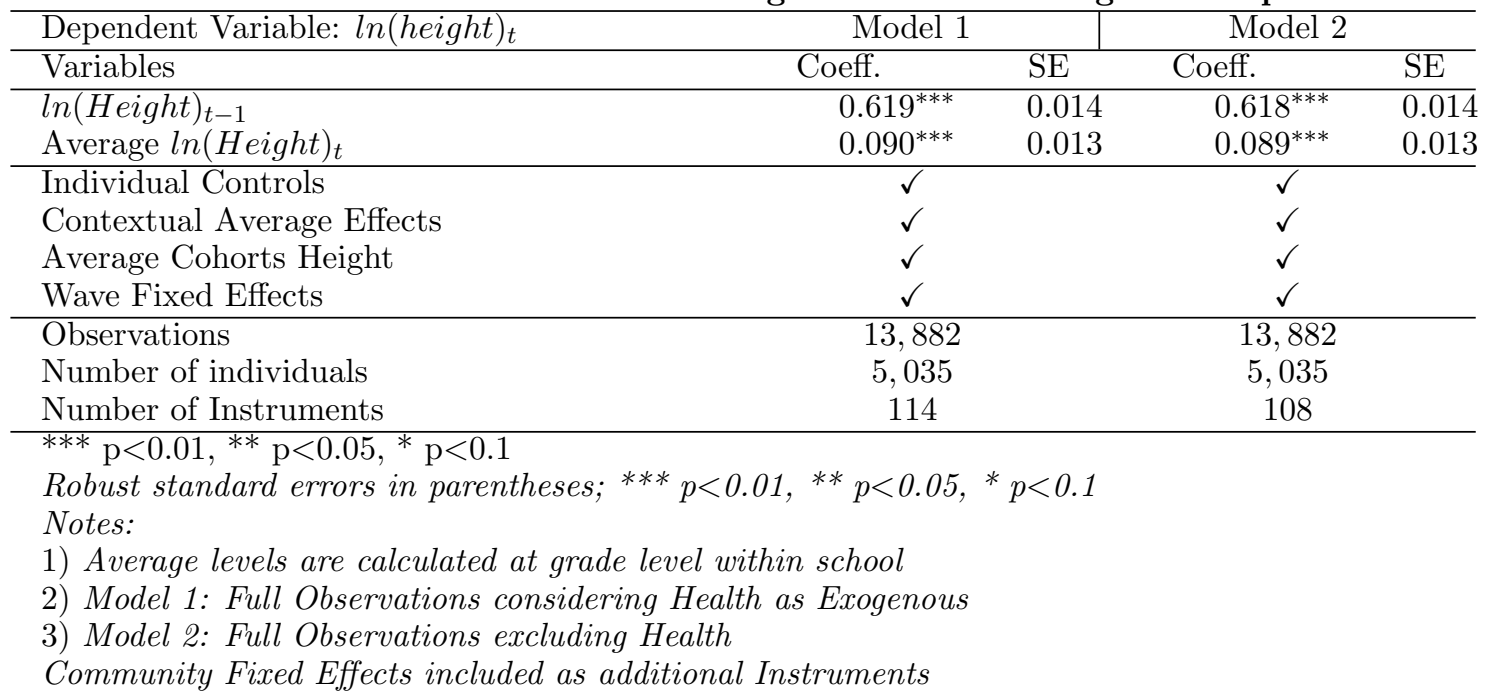

\section{D.2 Robustness Test: BMI adjusted for Gender and Age}

We provide additional evidence on BMI adjusted for age and gender (zBMI). The zBMI growth curve for boys and girls are different and the cut-off levels for both genders are non identical. We estimate our empirical model (5) for both males and females for the three categories (normal, over-weight and obese). The reference levels for zBMI are obtained as the z-score per-

\footnotetext{
${ }^{3}$ We also conducted separate estimations by dividing the sample by gender in three height categories (short, medium and tall) and found that the peer effect for the female sample is not significant or weakly significant. Whereas for the male sample the peer effect is significant but very small. The results are available upon request.

${ }^{4}$ Other available variables like having acne/asthma problems are binary variables (having or not skin/asthma problems) or are not available in all waves (such as ADHD - Attention Deficit Hyperactivity Disorder) so they are not suitable to be used in a falsification test via GMM.
} 
centiles from the table classification produced by the $\mathrm{WHO}^{5}$. The results are slightly different as compared to our baseline estimations. For the sample of males the results in Table D.2 show that current BMI of normal-weight and obese boys is affected by past BMI and peer effects with a similar magnitude. The opposite effect occurs for the sample of over-weight boys where past BMI is not significant anymore, whereas the peer effect explains most of the current BMI variation. The estimation for the female sample are presented in Table D.3: both past and peer effects are relevant in explaining current BMI, with the past effects having a stronger impact on current BMI in all the three weight categories.

Table D2: Estimates using full sample of Males for Adjusted BMI by age

\begin{tabular}{lcccc}
\hline Dependent Variable: $\ln (B M I)_{t}$ & Model 1 & \multicolumn{2}{c}{ Model 2} & \\
\hline Variables & Coeff. & SE & Coeff. & SE \\
\hline Boys normal-weight during adoles- & & & & \\
cence & & & & \\
$\ln (B M I)_{t-1}$ & $0.569^{* * *}$ & 0.028 & $0.571^{* * *}$ & 0.027 \\
Average $\ln (B M I)_{t}$ & $0.349^{* * *}$ & 0.042 & $0.341^{* * *}$ & 0.042 \\
\hline Observations & 3,718 & & 3,718 & \\
Number of individuals & 1,896 & & 1,896 & \\
Number of Instruments & 106 & & 104 & \\
\hline Boys over-weight during adolescence & & & & \\
$\ln (B M I)_{t-1}$ & -0.151 & 0.114 & 0.151 & 0.113 \\
Average $\ln (B M I)_{t}$ & $0.548^{* * *}$ & 0.113 & $0.548^{* * *}$ & 0.113 \\
\hline Observations & 312 & & 312 & \\
Number of individuals & 165 & & 165 & \\
Number of Instruments & 82 & & 82 & \\
\hline Boys obese during adolescence & & & & \\
$\ln (B M I)_{t-1}$ Average $l n(B M I)_{t}$ & $0.558^{* * *}$ & 0.126 & $0.621^{* * *}$ & 0.123 \\
Observations & $0.505^{* * *}$ & 0.369 & $0.560^{* * *}$ & 0.188 \\
Number of individuals & 169 & & 169 & \\
Number of Instruments & 85 & & 85 & \\
\hline Individual Controls & 65 & & 63 & \\
Contextual Average Effects & $\checkmark$ & & $\checkmark$ & \\
Average Cohorts BMI & $\checkmark$ & & $\checkmark$ & \\
Wave Fixed Effects & $\checkmark$ & & $\checkmark$ & \\
\hline$* * *$ & & & & \\
\hline
\end{tabular}

*** $p<0.01,{ }^{* *} p<0.05,{ }^{*} p<0.1$

Notes:

1) Average levels are calculated at Grade level within Schools

2) Model 1: Full Observations considering Health as Exogenous

3) Model 2: Full Observations excluding Health

4) Community Fixed Effects included as Additional Instruments

\footnotetext{
${ }^{5}$ The z-scores tables and percentiles are retrieved from https://www.who.int/childgrowth/standards/bmi for age/en/
} 
Table D3: Estimates using full sample of Females for Adjusted BMI by age

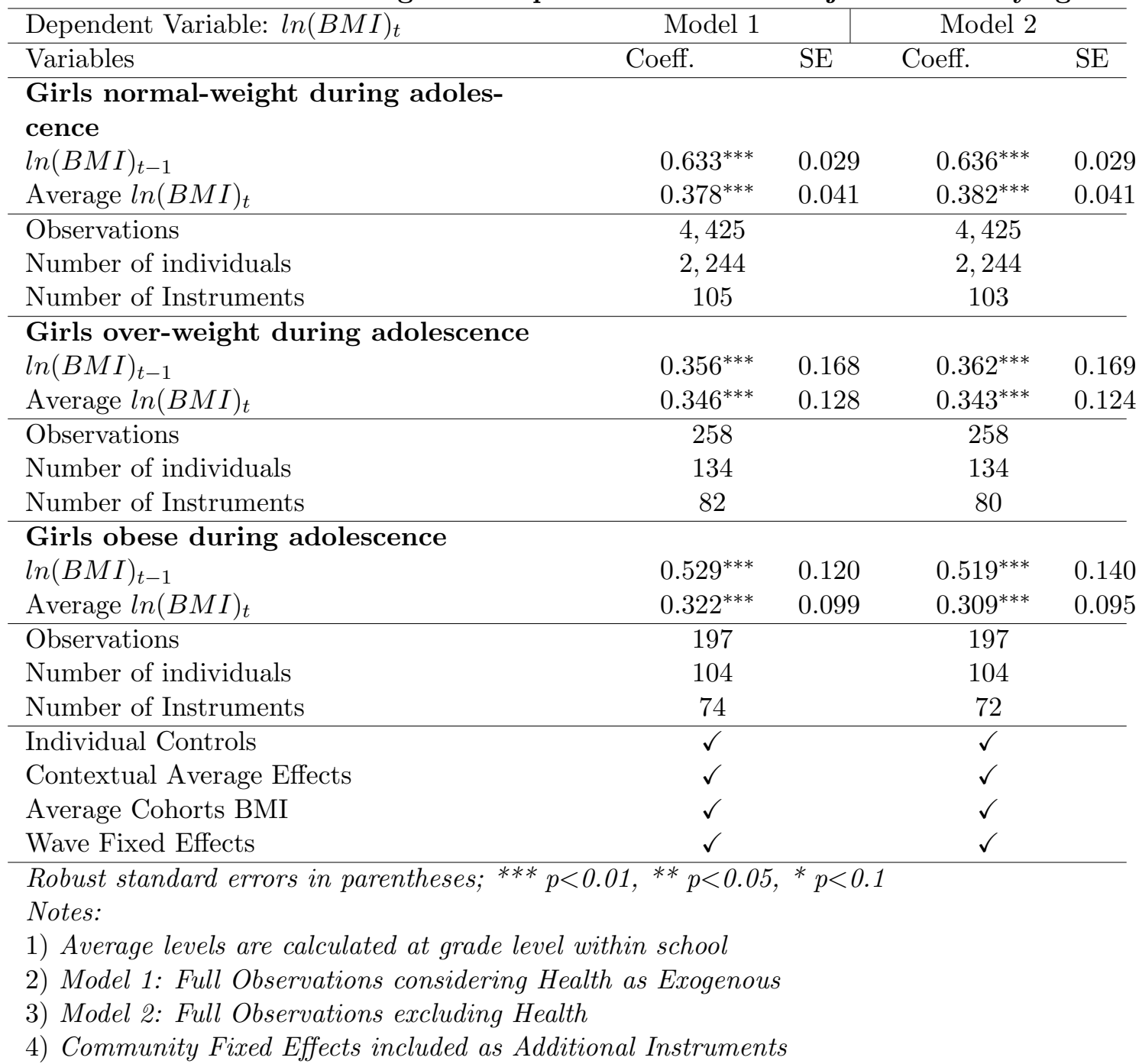

